in vivo $35: 1929-1938(2021)$

doi:10.21873/invivo.12459

Review

\title{
Osteoid Osteoma: An Updated Review of Epidemiology, Pathogenesis, Clinical Presentation, Radiological Features, and Treatment Option
}

\author{
KOSTAS TEPELENIS ${ }^{1}$, GEORGIOS P. SKANDALAKIS ${ }^{2}$, GEORGIOS PAPATHANAKOS ${ }^{3}$, \\ MARIA ALEXANDRA KEFALA ${ }^{4}$, AIKATERINI KITSOULI ${ }^{4}$, ALEXANDRA BARBOUTI $^{5}$, \\ NIKOLAOS TEPELENIS ${ }^{6}$, DIMITRIOS VARVAROUSIS ${ }^{4}$, KONSTANTINOS VLACHOS $^{1}$, \\ PANAGIOTIS KANAVAROS ${ }^{5}$ and PANAGIOTIS KITSOULIS ${ }^{5}$ \\ ${ }^{1}$ Department of Surgery, University Hospital of Ioannina, Ioannina, Greece; \\ ${ }^{2}$ Department of Neurosurgery, Icahn School of Medicine at Mount Sinai, New York City, NY, U.S.A.; \\ ${ }^{3}$ Intensive Care Unit, University Hospital of Ioannina, Ioannina, Greece; \\ ${ }^{4}$ University of Ioannina, Ioannina, Greece; \\ ${ }^{5}$ Anatomy - Histology - Embryology, University of Ioannina, Ioannina, Greece; \\ ${ }^{6}$ Department of Pathology, Agia Sofia Children's Hospital, Athens, Greece
}

\begin{abstract}
Osteoid osteoma, the third most common benign bone tumor, usually occurs in the cortex of long bones. It consists of a radiolucent nidus surrounded by reactive osteosclerosis. Generally, osteoid osteoma affects young males. Nocturnal pain that eases with salicylates or nonsteroidal anti-inflammatory drugs (NSAID) is the typical clinical presentation. Sometimes, it remains undiagnosed for a long time. Plain radiography and computed tomography are usually sufficient for the diagnosis of osteoid osteoma. Initial treatment includes salicylates and NSAID because the tumor often regresses spontaneously over 2-6 years. Surgical treatment is indicated in case of unresponsive pain to medical therapy, no tolerance of prolonged NSAID therapy due to side effects, and no willingness to activity limitations. Nowadays, minimally invasive techniques have replaced open surgery and are considered the gold standard of surgical treatment. Although cryoablation seems superior in terms of the nerve damage and immunotherapy effect, radiofrequency ablation is the preferred technique.
\end{abstract}

This article is freely accessible online.

Correspondence to: Kostas Tepelenis, MD, MSc, Vellas 30, Kardamitsia, Ioannina, Greece. Tel: +30 2651038047, Fax: +30 2651077630,e-mail: kostastepelenis@gmail.com

Key Words: Osteoid osteoma, imaging, medical therapy, en-bloc resection, percutaneous ablation, review.
Osteoid osteoma is a benign, usually solitary bone-forming tumor accounting for $10-14 \%$ of all benign- and $2-3 \%$ of all primary-bone tumors (1). It was first described by Bergstrand in 1930 and characterized by Jaffe as an entity in 1935 (2). Typical features encompass the radiolucent nidus, the small size (less than $2 \mathrm{~cm}$ in diameter) and the surrounding reactive osteosclerosis. It usually affects young males less than 30 years old and is often localized in the cortex of long bones (3-5). Nocturnal pain that alleviates with salicylates or nonsteroidal anti-inflammatory drugs (NSAIDs) should raise suspicion for the presence of osteoid osteoma (2). In a young active individual, it is not unusual to have the symptoms for quite a long time, while the case remains undiagnosed (6).

Plain radiography and computed tomography are usually sufficient to diagnose osteoid osteoma $(6,7)$. Initially, treatment of these tumors is conservative with salicylates or NSAIDs as some tumors regress spontaneously over 2-6 years (8-10). In case of failure, surgical management is mandatory. Nowadays, minimally invasive techniques have replaced traditional open surgery techniques and are now considered as the gold standard of treatment. Although success and complication rates between radiofrequency ablation and cryoablation are equal, radiofrequency ablation is the preferred technique (11).

In a previous article, we have summarized the epidemiological, clinical, radiological, and histopathological features of osteoid osteoma. The purpose of the present article is to review the updated findings regarding epidemiology, 
pathogenesis, clinical presentation, imaging findings, treatment options, and prognosis of osteoid osteoma.

\section{Epidemiology}

Osteoid osteoma represents the third most common benign bone tumor after enchondroma and non-ossifying fibroma (12). It accounts for $10-14 \%$ of all benign bone tumors and $2-3 \%$ of all primary bone tumors $(1,13,14)$. Individuals 530 years old are more susceptible to the development of osteoid osteoma; a peak incidence is noted during the second decade of life $(1,2,5)$. It is estimated that $70 \%$ of osteoid osteomas develop in patients younger than 20 years $(6,15)$. People older than 30 years and children younger than 5 years are less commonly affected, with $13 \%$ and $3 \%$ incidence, respectively $(16,17)$. Moreover, osteoid osteoma shows a male predominance (male to female ratio 2-3:1) $(1,2,5)$.

The appendicular skeleton is the commonest locus of osteoid osteoma. Osteoid osteoma is seldom seen in the axial skeleton, except for the spine, with lower extremities being more frequently affected than the upper extremities. More than half of the osteoid osteomas occur in the lower extremities, especially in the femur and tibia. In the upper extremities, the humerus is the commonest area of involvement followed by the ulna and radius (3).

Approximately $6-20 \%$ of osteoid osteomas occur in the spine. The tumor predominately develops in the posterior elements like spinous processes, transverse processes, lamina, pedicles, and facets. The lumbar spine is the preferred site of occurrence, followed by the cervical spine, the thoracic spine, and the sacrum $(2,5,13,18)$.

Small bones of the feet and hands are affected less frequently. The talus is involved in $2-10 \%$ of cases, followed by the calcaneus $(2.7 \%)$, phalanges $(2 \%)$, and metatarsals $(1.7 \%)(19,20)$. Jackson et al. reported that $10 \%$ of osteoid osteoma involve the hand: $6 \%$ the phalanges, $2 \%$ the metacarpal bones, and $2 \%$ the carpal bones (19). In a recent study, Erdogan et al. evaluated 9 hand osteoid osteoma cases. They found that $67 \%$ of the tumors developed in the proximal phalanx, $22 \%$ in the middle phalanx, and $11 \%$ in the metacarpal (21). The involvement of the skull and facial bones is exceptionally rare $(22,23)$.

\section{Classification}

The classification of osteoid osteomas depends on its location. Osteoid osteomas are classified as intracortical, subperiosteal, endosteal, and medullary (24). The commonest type is intracortical lesions (75\%), followed by medullary (20\%), subperiosteal, and endosteal lesions (both 5\%) (4). Intracortical lesions are usually located in the diaphysis or metaphysis of the long tubular bones like the tibia and femur. Medullary tumors are typically juxta-articular in location and are often observed in the femoral neck, hands, feet, and posterior elements of the spine. Subperiosteal osteoid osteomas are situated on the cortex's external aspect, whereas endosteal tumors are found on the cortex's internal aspect. Subperiosteal tumors are normally apparent along the medial aspect of the femoral neck, hands, feet, and neck of the talus $(4,25)$.

\section{Pathophysiology}

The pathogenesis of osteoid osteoma remains controversial. Some authors suggest that osteoid osteoma is a benign bone tumor, while others believe it may represent an inflammatory process or unusual healing. The tumor's histological similarity to osteoblastoma and the presence of atypical cellular and trabecular component support the hypothesis that osteoid osteoma is a benign tumor derived from osteoblasts. Features like the relatively small size, the self-limited nature, and the presence of intracellular viral particles favor the inflammatory process. Additionally, extremely high levels of prostaglandins have been found in osteoid osteomas, which may play an essential role in developing these tumors $(2,6)$. Some authors propose that the lesion is an attempt at repair but with no evidence of fracture, infarction, or infection (2). The vascular nature of the lesion has been demonstrated by angiography. A small feeding artery has been seen in the early arterial phase and a contrast filling of the nidus has been obtained during angiography (26).

Prostaglandins are considered to be responsible for pain generation. According to Healey et al., prostaglandins increase the vessels' diameter and permeability, raising the vessels' size and flow in the bony lesion, and finally increasing pressure and pain. Alternatively, prostaglandins affect the bradykinin system, amplifying pain, just like injured soft tissues (27). Besides, the response to salicylates or NSAIDs, which affect prostaglandins synthesis, demonstrates the fundamental role of prostaglandins in the pathophysiology of pain $(2,5)$.

\section{Gross Pathology and Histopathology}

Macroscopically, osteoid osteoma is a well-circumscribed tumor, red in color with soft and friable composition and a dimeter of $1.5-2 \mathrm{~cm}$. Its consistency rises, and its reddish color lessens due to the central part of the nidus' osseous maturation, either spontaneously or after treatment. These changes are in proportion to the degree of bone tissue maturation (5).

Histologically, it is composed of a central nidus, which contains sheets of immature woven bone, occasionally with osteoblastic rimming, scattered osteoclasts in the fibrous connecting tissue that separates the osteoid trabeculae, and vascular spaces of small and intermediate size. There is a zone of solid, mature bone in the periphery of the lesion that surrounds the nidus (5). 


\section{Clinical Presentation}

Pain is the predominant symptom and is described as a dull, constant, aching, and intense pain with varying severity. Initially, the pain is mild and intermittent but increases in intensity and persistence over time. The pain usually deteriorates at night and lessens by morning. It is characteristically alleviated by salicylates and NSAIDs (2, 5). Swelling can sometimes be the only symptom, especially in the diaphyseal lesions (13).

When localized in the spine, individuals ordinarily present with painful scoliosis due to paravertebral muscle spasm. The incidence of scoliosis is variable $(4.5-100 \%)$ (28-30). The tumor is typically located at the apex of convexity. If the tumor is misdiagnosed for a long time, scoliosis becomes postural. However, deformity resolves with early resection, within 18 months, especially in children younger than 11 years $(6,17)$. Cervical lesion manifests with painful torticollis and reduced cervical range of movements instead of scoliosis. Neurologic deficits are seen in $0-30 \%$ of patients with spinal osteoid osteoma (28-30).

Osteoid osteoma in the vicinity of the proximal femur or pelvis can cause knee pain, and the diagnosis may require a bone scan (13). An intra-articular lesion may produce synovitis with joint effusion and decreased range of motion can be noticed $(2,6)$. If the lesion is close to an open physis, it might bring about lengthening and/or angular deformity of the extremity $(5,17)$. Finally, an osteoid osteoma located in the hand can provoke monoarticular arthritis, macrodactyly, clubbing, painless swelling, and absence of bone lysis $(31,32)$.

\section{Natural History}

The course of the disease is unpredictable, protracted, and depends on the tumor's location. If misdiagnosed, it can cause bone widening and deformation or even length discrepancy and angular deviation when located near a growth plate $(5,17)$. If a joint is involved, synovitis and limited motion can be noticed $(2,6)$. Moreover, spinal tumors result in painful scoliosis or torticollis depending on the location (28-30).

Occasionally, osteoid osteoma might heal spontaneously after a period ranging from 3-7 years (5). Atar et al. described two stages of the disease: The first stage is characterized by pain lasting 18-36 months, during which the steadily use of analgesics is necessary. The second stage includes the healing of the nidus, which usually takes 3-7 years (33). In the past, authors reported a spontaneous regression of clinically and radiologically diagnosed osteoid osteoma during an average of 6 years (range=2-15 years). Unfortunately, there was no histological confirmation in these cases $(2,8)$.

\section{Imaging}

Plain radiography. In most cases, plain radiography combined with the characteristic clinical presentation is required to establish an osteoid osteoma diagnosis. Plain radiography should be the first imaging modality to assess patients with bone pain. At least two orthogonal views centered over the lesion should be obtained (6). The radiographic appearance of the tumor depends on its location within the involved bone. Lesions located in certain areas of the skeleton are difficult to evaluate by radiographs. These areas encompass the spine, the femoral neck, and the hands and feet' small bones (34). In a meta-analysis of 223 patients with an osteoid osteoma in the hands and feet, Jordan et al. reported that plain radiography had a detection rate of only $66 \%$ (20).

The typical lesion is a round or oval radiolucent area measuring less than $1.5-2 \mathrm{~cm}$. This area is surrounded by fusiform sclerosis to a varying degree $(12,25)$. Central calcification is often observed in the radiolucent nidus (35). Occasionally sclerosis and cortical thickening may obscure the nidus (5). Rarely, the nidus appears as a bone island or normal cortical bone due to complete ossification (36).

The degree of sclerosis surrounding the nidus depends on the tumor's location. Diaphyseal lesions exhibit more sclerosis than epiphyseal and metaphyseal lesions. In cortical tumors, sclerosis is considerable, whereas medullary tumors provoke less sclerosis than their intracortical counterparts. Subperiosteal lesions demonstrate minimal sclerosis and may appear as soft tissue lesions adjacent to the affected bone. Worth noting is that long-lasting tumors produce more sclerosis. Children also display more sclerosis than adults $(4,37)$.

In subarticular and intracapsular tumors, sclerosis may be absent or minimal or occur at a distance from the lesions. This phenomenon is usually seen in tumors of the femoral neck; the femoral neck periosteum is different and unable to provoke evident cortical thickening $(25,38,39)$. The lack of cambium, the femoral neck periosteum's inner cellular layer, is responsible for the minimal or absent cortical thickening (12). The femoral neck surface has significant less cellular periosteum compared to the femoral diaphysis (40). However, an intraarticular osteoid osteoma might provoke bone sclerosis at a distance from its location, for example in the upper part of the underlying femoral shaft $(25,35)$.

Computed tomography $(C T)$. CT is the modality of choice for the diagnosis of osteoid osteoma; it is superior to plain radiography for detecting these tumors, especially in areas that are difficult to image on plain radiography (Figure 1) (7, 41). According to several authors, the detection rate of spinal osteoid osteomas by CT is almost $100 \%(34,42)$. Jordan et al. reported that osteoid osteoma's detection rate in hand and foot is $96.5 \%$ (20). Assoun et al. compared the diagnostic accuracy of CT and magnetic resonance imaging in 19 
patients with histologically proven osteoid osteoma before excising the lesion. The authors found that $\mathrm{CT}$ was more accurate than magnetic resonance imaging in detecting the osteoid osteoma nidus in $63 \%$ of cases (43).

Typically, osteoid osteoma shows up as a well-defined round or oval area of soft-tissue attenuation. The lesion is surrounded by reactive sclerosis, which varies from being amazingly dense to showing no reaction. The nidus enhances after the intravenous administration of the contrast agent (4). The calcified center of the nidus, known as the "bulls-eye" appearance, is visible on CT in about $50 \%$ of cases $(25,43)$. Calcification of the nidus is characterized as punctate, amorphous, or ring-like (4). Osteoid osteomas are frequently surrounded by thin linear or serpentine grooves in the surrounding bone. These grooves represent the presence of enlarged arterioles delivering blood from the periosteum to the nidus (44). This finding is called the "vascular groove" sign and can be detected in about $80 \%$ of cases $(45,46)$. Liu et al. found that the "vascular groove" sign was moderately sensitive but highly specific for the differentiation of osteoid osteoma from other radiolucent bone tumors (47).

Magnetic resonance imaging (MRI). MRI is inferior to CT for detecting and characterizing osteoid osteoma (6). If used as the primary imaging modality, the risk of misdiagnosis is $35 \%(20,43,48)$. Nevertheless, MRI can be beneficial in certain cases as it demonstrates cortical involvement and intramedullary and soft tissue spread (Figure 2). Also, it is excellent in illustrating the nidus in cases of intra-articular lesions (6).

The nidus generally displays low to intermediate signal intensity on T1-weighted images and heterogeneous high signal intensity on T2-weighted and short tau inversion recovery (STIR) images $(7,43,48)$. Perilesional sclerosis and central calcifications exhibit low signal intensity with both T1-weighted and T2-weighted sequences $(4,12)$. After the administration of gadolinium, osteoid osteoma enhances on T1-weighted images. Several authors reported that osteoid osteoma shows a peak in signal enhancement during the arterial phase in $82 \%$ of the cases $(46,49,50)$. Bone marrow oedema around the nidus is illustrated in $60 \%$ of cases, whereas soft tissue oedema adjacent to the lesion is visible in over half of the patients. Intra-articular tumors cause synovitis and joint effusion, which can be evident on MRI $(39,51,52)$.

Nuclear imaging. Scintigraphy examines metabolic activity and detects new bone lesions through whole-body images in a single examination (53). Bone scintigraphy using $99 \mathrm{mTc}$ detects osteoid osteoma by increasing activity at the tumor site with a reported sensitivity of nearly $100 \%(54,55)$. The classic finding is the "double density" sign, which consists of a focal area with increased uptake, surrounded by a less

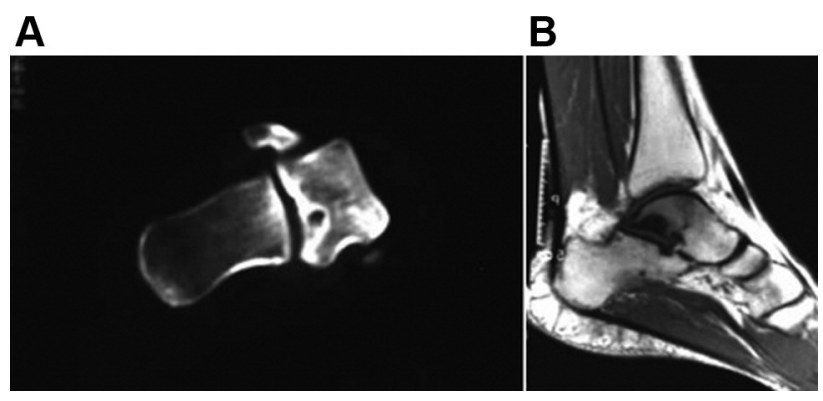

Figure 1. Computed tomography (A) and magnetic resonance imaging (B) scans of an osteoid osteoma located in the talus. Reprinted with permission (6).

A
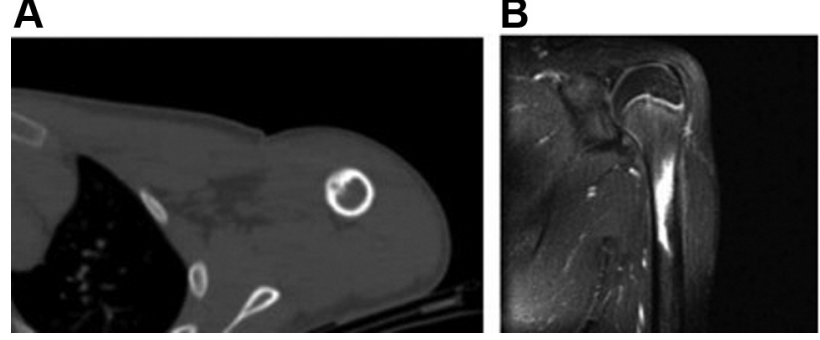

Figure 2. Cortical location of osteoid osteoma in the diaphysis of the humerus [computed tomography (A) and magnetic resonance imaging (B) scans]. Reprinted with permission (6).

dense uptake area. The central area represents the nidus and the surrounded area the host bone tumor response. Although this sign is very specific in the appendicular skeleton, it is less frequently visible in the spine due to the less osteosclerosis in the vertebrae $(35,56,57)$.

Single photon emission computed tomography (SPECT) imaging with three-dimensional reconstruction techniques is a valuable tool for detecting small lesions and lesions in areas with complex anatomy such as the posterior elements of the spine (58-60). In a retrospective study, Sharma et al. compared the sensitivity, specificity and accuracy of SPECT/CT, CT, and planar bone scintigraphy in 39 patients with osteoid osteoma; authors concluded that SPECT/CT had significantly higher sensitivity, specificity and accuracy (all $100 \%)$ compared to CT $(77.8 \%, 92.3 \%$, and $83.8 \%$, respectively) and planar bone scintigraphy $(100 \%, 38.4 \%$, and $74.1 \%$, respectively) (61). Radionuclide imaging can be also used intraoperatively to localize the tumor and establish the complete removal of the nidus (6).

18-fluorodeoxyglucose positron-emission tomography $\left({ }^{18} \mathrm{~F}\right.$ FDG PET/CT). ${ }^{18} \mathrm{~F}$-FDG PET/CT may have a role in the diagnosis of osteoid osteoma. It is normally used in the 
diagnosis of malignant tumors as ${ }^{18} \mathrm{~F}-\mathrm{FDG}$ accumulates in proliferating cancer cells. It has also been used to diagnose osteoid osteoma since ${ }^{18}$ F-FDG intensely accumulates in these tumors $(62,63)$. Some authors evaluated its use as a tool to monitor response to therapy. They found a significant reduction of ${ }^{18} \mathrm{~F}$-FDG uptake after successful radiofrequency ablation (63). Nonetheless, ${ }^{18}$ F-FDG PET/CT may produce false-negative results in detecting osteoid osteoma (4).

\section{Treatment}

Initially, osteoid osteoma management is conservative with salicylates or NSAIDs as some tumors regress spontaneously over 2-6 years $(8,9)$. Indications for surgical intervention encompass unresponsive pain to medical therapy, no tolerance of prolonged NSAID therapy due to side effects, and no willingness to activity limitations. For decades, surgical treatment with open en-bloc resection or curettage was considered the gold standard in treating osteoid osteoma. However, this kind of surgical treatment is invasive and has potential complications $(4,64)$. Recently, minimally invasive techniques, especially radiofrequency ablation, laser ablation and cryoablation, have become the most widely and validated methods for treating osteoid osteoma. These techniques' two main advantages are lower invasiveness and lower cost $(11,50)$.

Medical therapy. Osteoid osteoma exhibits a self-limited course over time. Salicylates and NSAIDs have been used for the treatment of these tumors with good results. These drugs inhibit prostaglandin synthesis leading to pain relief. The main reasons for conservative treatment failure are persistent pain despite the therapy, reduction of drugs' initial effect over time, and little tolerance for ongoing pain among young, active patients who opt for an aggressive surgical alternative (15).

The response rate to salicylates and NSAIDs varies from study to study. Pettine et al. reported a success rate of $90 \%$ after the administration of aspirin or NSAIDs (65). Healey et al. noted that $73 \%$ of patients receiving aspirin $650-3250$ $\mathrm{mg}$ /day displayed pain relief (27), while Kirchner et al. found that the success rate ranged from $30-75 \%$ after the administration of aspirin (66). Rofecoxib, a selective cyclooxygenase- 2 inhibitor, displayed a better response to pain compared to conventional NSAIDs (67). It exhibited a significant reduction in pain at rest during the day than did aspirin. It also showed a trend toward lower pain at night and pain induced by exercise (68). Other drugs like bisphosphonates were successful in $83 \%$ of cases. The longterm final success was achieved in $74 \%$ of patients (69).

Surgical treatment. In the past, surgical treatment was the treatment of choice for patients with an osteoid osteoma in whom conservative treatment failed. The aim of surgical treatment is the complete removal of the nidus to minimize the risk of relapse. Two surgical excision techniques are available: En-bloc resection of the lesion and the surrounding bone and curettage $(39,64)$. Prophylactic internal fixation is indicated if a substantial cortex is resected and if the remaining bone is weakened, while spinal fusion is carried out in case of instability (27).

The efficacy of surgical treatment is high (4). The reported success rate for en-bloc resection is $88-100 \%$ (64), while arthroscopic management of intra-articular tumors is successful in $90 \%$ of cases (70). Disadvantages of surgical treatment encompass general anesthesia risks, prolonged hospitalization, rehabilitation, and insufficiency fractures at the site of excision (4). Technical aspects include the difficulties in detecting the tumor intraoperatively and identifying the exact amount of bone to resect (64).

Intraoperative localization and identification of the nidus guided by CT or $99 \mathrm{mTc}$ have been reported (6). Additionally, intraoperative radiographic guidance through 2-D navigation with the $\mathrm{C}$-arm and recently with 3 -D navigation with the $\mathrm{O}$ arm has been also described $(71,72)$.

\section{Minimally invasive techniques}

CT-guided percutaneous excision. CT-guided percutaneous excision is an alternative surgical technique. It is carried out under local anesthesia and CT-guidance. A needle is inserted into the nidus under CT-guidance. Then, a small incision is performed, a biopsy punch is inserted through the needle and the specimen is removed. Postoperative CT is performed to confirm complete evacuation of the nidus. Finally, a pathologic examination is done to confirm the diagnosis. The proper placement of the needle into the nidus is crucial as it decreases the amount of bone that will be resected during the surgery and reduces the risk of postoperative fracture (33, 73). The success rate of this method is $83-100 \%$ (74-78).

Percutaneous ablation. Radiofrequency ablation, first described in the early 1990s, uses high-frequency electrical current to destroy tumors thermally. A needle is placed in the lesion under CT-guidance and a high-frequency electrical current is passed through an electrode in the needle, creating a small heat region. The heat induces coagulation necrosis of all tissue in a defined area around the electrode (11). This method has a success rate of 94-95\% (79, 80). Lanza et al. analyzed 27 articles consisted of 1,772 patients with osteoid osteoma and found a success rate of $95 \%$ (81).

Cryoablation. Cryoablation, first described in 2010, uses freeze and thaw to destruct tumors. A thin wandlike needle (cryoprobe) is inserted into the tumor under CT-guidance and a gas (argon gas or carbon dioxide) is pumped into the cryoprobe to freeze the tumor. Then, the tumor is allowed to thaw. Cell death is induced by repeated cycles of rapid freezing and thawing with a temperature below $-40^{\circ} \mathrm{C}(82)$. The success 
rate of the technique is $95.2 \%$ (83). Whitmore et al. studied 29 patients (mean age 11,3 years, range $=1-18$ years, $58.6 \%$ boys) with suspected osteoid osteoma. The authors concluded that short term clinical success (cessation of pain and NSAID use for $>3$ months after the procedure) was $96 \%$. In contrast, longterm clinical success (cessation of pain and NSAID use for $>$ 12 months after the procedure) was $90.5 \%$ (84).

Microwave ablation. Microwave ablation, first described in 2014, uses microwaves to ablate tumors thermally. A needle is inserted into the lesion under CT-guidance and microwaves produced by the needle create a small heat region that heats and destroys the tumor $(85,86)$. Microwave ablation is less affected by the type of tissue or tissue impedance than radiofrequency ablation (87). This method is highly successful (85).

A recent systematic review and pooled analysis assessed the efficacy and safety of percutaneous ablation (radiofrequency ablation, cryoablation, and microwave ablation) in patients with osteoid osteoma. A total of 36 articles comprising 1,798 patients were included. The overall success rate was $91.9 \%$ and highlighted that percutaneous ablation is an effective therapeutic alternative to open surgery. There were no differences between radiofrequency ablation and cryoablation regarding outcomes. However, the evidence demonstrated that cryoablation eliminated the risk of permanent nerve damage and showed an immunotherapy effect. Further evidence indicated that both motor and sensory nerves regenerate following (intentional and unintentional) cryoablation, which may improve ablations' safety near critical nerves and the spinal cord. Although microwave ablation exhibits promising results, the literature's lack of data forbidden its statistical comparison of efficacy (11).

Magnetic resonance-guided focused ultrasound. Magnetic resonance-guided focused ultrasound is an innovative imagingguided technique that permits the ablation of osteoid osteoma without radiation. It seems that this method is an effective and safe alternative in the treatment of osteoid osteoma in both children and adults $(88,89)$. Geiger et al. described the outcomes of 29 patients with non-spinal osteoid osteoma treated with magnetic resonance-guided focused ultrasound; the mean age of the patients was 25 years. The authors found that the complete clinical success was $90 \%$, and the partial success $10 \%$ (88).

\section{Prognosis}

According to Healey et al., en-bloc excision showed the lowest recurrence rate, while curettage and intralesional resection had the highest (27). Sluga et al. studied 106 patients with osteoid osteoma treated by conventional surgical methods. The authors noted that relapse was less frequent after en-bloc excision than curettage (4.5\% vs. 12\%) (90). Open surgery complications include perioperative fractures, prolonged hospital stay, delayed functional recovery, and the need for bone grafts or internal fixation (4, 27). In Sluga et al., postoperative fractures were observed in $4.5 \%$ after en-bloc resection and in 3\% after curettage (90).

The relapse rate of CT-guided percutaneous excision is 0 $12.5 \%(74,76,78)$. Complications include postoperative fractures, hematoma, infection, nerve damage, and osteomyelitis. Sans et al. noted a complication rate of $24 \%$ (77), whereas Raux et al. reported two femoral fractures (4.7\%) (78), Donahue et al. one minor complication (4.7\%) (76) and Roger et al. no complications at all (0\%) (74).

The relapse and complication rate of percutaneous ablation varies between studies. Complications include skin burns, hematoma, infection, and nerve damage. In Lanza's systematic review concerning radiofrequency ablation, the failure rate was $5 \%$ and the complication rate meager $(2 \%)$. In most cases, complications were minor. Because not all investigators reported the exact time of recurrence, it was impossible to associate recurrences with time (81). A recent systematic review included 69 studies with 3,023 patients with osteoid osteoma treated by radiofrequency ablation. The global primary treatment failure was $8.3 \%$, whereas the secondary treatment failure was $3.1 \%$. Age, tumor location, and duration of ablation (6 min vs. greater than $6 \mathrm{~min}$, at $90^{\circ} \mathrm{C}$ ) had no impact on treatment failure. Concerning the time period, treatment failure in the later period of studies examined between 2011-2019 was approximately half that of the earlier period 2002-2010 (7\% vs. $14 \%$ ). The overall complication rate was $3 \%$, with skin burns being the most frequent (91).

In terms of cryoablation, Santiago et al. reported a recurrence rate of $4.8 \%$ and a complication rate of $14.3 \%$ without any major complication (83). Similarly, Whitmore et al. reported a minor complication rate of $21 \%$ and no major complications in 29 patients with osteoid osteoma treated by cryoablation (84).

In the recent systematic review and analysis by Lindquester et al., success and complication rates between radiofrequency ablation and cryoablation were similar with the reported rate of failure being $5.6 \%$ for all modalities. Recurrent disease was responsible for the majority of failures and a second ablation treated successfully $71.2 \%$ of the recurrences. Even though most recurrences happened in the first few months, some occurred years after the ablation. This highlights the importance of long-term follow-up of these patients; complication rate was exceptionally low (2.5\%) (11).

\section{Conclusion}

Osteoid osteoma is the third most common benign bone tumor and normally occurs in the cortex of long bones. It is composed of a radiolucent nidus and surrounding sclerotic bone. Typically, osteoid osteoma usually affects individuals 5-30 years and shows a male predominance. Pain is the 
predominant symptom that usually deteriorates at night and eases with salicylates or NSAIDs. Plain radiography and CT are the mainstays of diagnosis. MRI can add significant value since it depicts cortical involvement and intramedullary and soft tissue spread. Radionuclide imaging can be used either preoperatively to diagnose or intraoperatively to localize the tumor and establish the complete removal of the nidus. The initial treatment of osteoid osteoma is conservative with salicylates and NSAIDs as some tumors regress spontaneously over 2-6 years. Although in the past, surgical excision (en-bloc resection or curettage) despite its complications was the gold standard in treating osteoid osteoma, recently, minimal invasive techniques have gained much popularity; they are efficient and safer compared to the surgical approach. Nowadays, they are regarded as the first-line treatment in case of failure of the conservative treatment. Success and complication rates between radiofrequency ablation and cryoablation are similar. Although radiofrequency ablation is the most favored technique, cryoablation seems superior in terms of nerve damage and immunotherapy effect. Microwave ablation is a promising method, but more data are needed to compare its statistical efficacy and safety.

\section{Conflicts of Interest}

The Authors report no conflicts of interest in relation to this study.

\section{Authors' Contributions}

Tepelenis K: Study conception and design; Skandalakis GP: Literature search and analysis; Papathanakos G: Critical revision; Kefala MA: Study conception and design; Kitsouli A: Draft of the work; Barbouti A: Critical revision; Tepelenis N: Draft of the work; Varvarousis D: Literature search and acquisition of data; Vlachos $\mathrm{K}$ : Analysis and interpretation of data; Kanavaros P: Analysis of articles from the literature; Kitsoulis P: Final approval of the version to be published. All the Authors agreed to be accountable for all aspects of the work in ensuring that questions related to the accuracy or integrity of any part of the work are appropriately investigated and resolved.

\section{References}

1 Zhang Y and Rosenberg AE: Bone-forming tumors. Surg Pathol Clin 10(3): 513-535, 2017. PMID: 28797500. DOI: 10.1016/j.path.2017.04.006

2 Lee EH, Shafi M and Hui JH: Osteoid osteoma: a current review. J Pediatr Orthop 26(5): 695-700, 2006. PMID: 16932114. DOI: 10.1097/01.bpo.0000233807.80046.7c

3 Bednar MS, Weiland AJ and Light TR: Osteoid osteoma of the upper extremity. Hand Clin 11(2): 211-221, 1995. PMID: 7635883.

4 Bhure U, Roos JE and Strobel K: Osteoid osteoma: multimodality imaging with focus on hybrid imaging. Eur J Nucl Med Mol Imaging 46(4): 1019-1036, 2019. PMID: 30341641. DOI: $10.1007 / \mathrm{s} 00259-018-4181-2$
5 Ghanem I: The management of osteoid osteoma: updates and controversies. Curr Opin Pediatr 18(1): 36-41, 2006. PMID: 16470160. DOI: 10.1097/01.mop.0000193277.47119.15

6 Kitsoulis P, Mantellos G and Vlychou M: Osteoid osteoma. Acta Orthop Belg 72(2): 119-125, 2006. PMID: 16768252.

7 Papathanassiou ZG, Megas P, Petsas T, Papachristou DJ, Nilas $\mathrm{J}$ and Siablis D: Osteoid osteoma: diagnosis and treatment. Orthopedics 31(11): 1118, 2008. PMID: 19226086. DOI: 10.3928/01477447-20081101-20

8 Kneisl JS and Simon MA: Medical management compared with operative treatment for osteoid-osteoma. J Bone Joint Surg Am 74(2): 179-185, 1992. PMID: 1541612.

9 Goto T, Shinoda Y, Okuma T, Ogura K, Tsuda Y, Yamakawa K and Hozumi T: Administration of nonsteroidal anti-inflammatory drugs accelerates spontaneous healing of osteoid osteoma. Arch Orthop Trauma Surg 131(5): 619-625, 2011. PMID: 20737157. DOI: $10.1007 / \mathrm{s} 00402-010-1179-\mathrm{z}$

10 Laliotis NA, Bindoudi AS, Tsitouridis IA, Petrakis IG and Kirkos JM: Osteoid osteoma of the acetabulum: diagnosis and medical treatment. J Pediatr Orthop B 26(6): 565-569, 2017. PMID: 28230613. DOI: 10.1097/BPB.0000000000000438

11 Lindquester WS, Crowley J and Hawkins CM: Percutaneous thermal ablation for treatment of osteoid osteoma: a systematic review and analysis. Skeletal Radiol 49(9): 1403-1411, 2020. PMID: 32270226. DOI: 10.1007/s00256-020-03435-7

12 Chai JW, Hong SH, Choi JY, Koh YH, Lee JW, Choi JA and Kang HS: Radiologic diagnosis of osteoid osteoma: from simple to challenging findings. Radiographics 30(3): 737-749, 2010. PMID: 20462991. DOI: 10.1148/rg.303095120

13 Boscainos PJ, Cousins GR, Kulshreshtha R, Oliver TB and Papagelopoulos PJ: Osteoid osteoma. Orthopedics 36(10): 792-800, 2013. PMID: 24093694. DOI: 10.3928/01477447-20130920-10

14 Hakim DN, Pelly T, Kulendran M and Caris JA: Benign tumours of the bone: A review. J Bone Oncol 4(2): 37-41, 2015. PMID: 26579486. DOI: 10.1016/j.jbo.2015.02.001

15 Barei DP, Moreau G, Scarborough MT and Neel MD: Percutaneous radiofrequency ablation of osteoid osteoma. Clin Orthop Relat Res (373): 115-124, 2000. PMID: 10810468. DOI: 10.1097/00003086-200004000-00014

16 Donkol RH, Al-Nammi A and Moghazi K: Efficacy of percutaneous radiofrequency ablation of osteoid osteoma in children. Pediatr Radiol 38(2): 180-185, 2008. PMID: 18040677. DOI: $10.1007 / \mathrm{s} 00247-007-0690-\mathrm{z}$

17 Frassica FJ, Waltrip RL, Sponseller PD, Ma LD and McCarthy EF Jr: Clinicopathologic features and treatment of osteoid osteoma and osteoblastoma in children and adolescents. Orthop Clin North Am 27(3): 559-574, 1996. PMID: 8649737.

18 Kan P and Schmidt MH: Osteoid osteoma and osteoblastoma of the spine. Neurosurg Clin N Am 19(1): 65-70, 2008. PMID: 18156049. DOI: 10.1016/j.nec.2007.09.003

19 Jackson RP, Reckling FW and Mants FA: Osteoid osteoma and osteoblastoma. Similar histologic lesions with different natural histories. Clin Orthop Relat Res (128): 303-313, 1977. PMID: 598169.

20 Jordan RW, Koç T, Chapman AW and Taylor HP: Osteoid osteoma of the foot and ankle - A systematic review. Foot Ankle Surg 21(4): 228-234, 2015. PMID: 26564722. DOI: 10.1016/j.fas.2015.04.005

21 Erdogan O and Gurkan V: Hand osteoid osteoma: evaluation of diagnosis and treatment. Eur J Med Res 24(1): 3, 2019. PMID: 30665467. DOI: 10.1186/s40001-019-0361-1 
22 Chahal A, Rajalakshmi P, Khan SA, Rastogi S, Srivastava DN and Gamanagatti S: CT-guided percutaneous radiofrequency ablation of osteoid osteoma: Our experience in 87 patients. Indian J Radiol Imaging 27(2): 207-215, 2017. PMID: 28744082. DOI: 10.4103/ijri.IJRI_260_16

23 Arrigoni F, Bruno F, Gianneramo C, Palumbo P, Zugaro L, Zoccali C, Barile A and Masciocchi C: Evolution of the imaging features of osteoid osteoma treated with RFA or MRgFUS during a long-term follow-up: a pictorial review with clinical correlations. Radiol Med 125(6): 578-584, 2020. PMID: 32040718. DOI: 10.1007/s11547-020-01134-w

24 Kayser F, Resnick D, Haghighi P, Pereira Edo R, Greenway G, Schweitzer M and Kindynis P: Evidence of the subperiosteal origin of osteoid osteomas in tubular bones: analysis by CT and MR imaging. AJR Am J Roentgenol 170(3): 609-614, 1998. PMID: 9490939. DOI: 10.2214/ajr.170.3.9490939

25 Kransdorf MJ, Stull MA, Gilkey FW and Moser RP Jr: Osteoid osteoma. Radiographics 11(4): 671-696, 1991. PMID: 1887121. DOI: 10.1148/radiographics.11.4.1887121

26 Lindbom A, Lindvall N, Soderberg G and Spjut H: Angiography in osteoid osteoma. Acta radiol 54: 327-333, 1960. PMID: 13762274. DOI: $10.3109 / 00016926009172555$

27 Healey JH and Ghelman B: Osteoid osteoma and osteoblastoma. Current concepts and recent advances. Clin Orthop Relat Res (204): 76-85, 1986. PMID: 3956019.

28 Raskas DS, Graziano GP, Herzenberg JE, Heidelberger KP and Hensinger RN: Osteoid osteoma and osteoblastoma of the spine. J Spinal Disord 5(2): 204-211, 1992. PMID: 1606380. DOI: 10.1097/00002517-199206000-00010

29 Ozaki T, Liljenqvist U, Hillmann A, Halm H, Lindner N, Gosheger $\mathrm{G}$ and Winkelmann W: Osteoid osteoma and osteoblastoma of the spine: experiences with 22 patients. Clin Orthop Relat Res (397): 394-402, 2002. PMID: 11953633. DOI: 10.1097/00003086-200204000-00046

30 Zileli M, Cagli S, Basdemir G and Ersahin Y: Osteoid osteomas and osteoblastomas of the spine. Neurosurg Focus 15(5): E5, 2003. PMID: 15323462 .

31 García-Vivar ML, Galindez E, Aróstegui J, García Llorente F, Uriarte E and Aramburu JM: Chronic monoarthritis caused by osteoid osteoma. An Med Interna 13(7): 344-346, 1996. PMID: 8962981.

32 Burger IM and McCarthy EF: Phalangeal osteoid osteomas in the hand: a diagnostic problem. Clin Orthop Relat Res (427): 198-203, 2004. PMID: 15552158. DOI: 10.1097/01.blo. 0000142623.97901 .39

33 Atar D, Lehman WB and Grant AD: Tips of the trade Computerized tomography - guided excision of osteoid osteoma. Orthop Rev 21(12): 1457-1458, 1992. PMID: 1465308.

34 Harish S and Saifuddin A: Imaging features of spinal osteoid osteoma with emphasis on MRI findings. Eur Radiol 15(12): 2396-2403, 2005. PMID: 15973540. DOI: 10.1007/s00330-0052816-8

35 Allen SD and Saifuddin A: Imaging of intra-articular osteoid osteoma. Clin Radiol 58(11): 845-852, 2003. PMID: 14581007. DOI: 10.1016/s0009-9260(03)00213-7

36 Jamshidi K, Shafipour R and Qomashi I: Osteoid osteoma with an atypical nidus: A case report. Foot Ankle Surg 18(1): e9-11, 2012. PMID: 22326016. DOI: 10.1016/j.fas.2011.09.003

37 Trotta B and Fox MG: Benign osteoid-producing bone lesions: update on imaging and treatment. Semin Musculoskelet Radiol
17(2): 116-122, 2013. PMID: 23673543. DOI: 10.1055/s-00331342968

38 Klein MH and Shankman S: Osteoid osteoma: radiologic and pathologic correlation. Skeletal Radiol 21(1): 23-31, 1992. PMID: 1546333. DOI: 10.1007/BF00243089

39 Malghem J, Lecouvet F, Kirchgesner T, Acid S and Vande Berg B: Osteoid osteoma of the hip: imaging features. Skeletal Radiol 49(11): 1709-1718, 2020. PMID: 32561955. DOI: 10.1007/s00256020-03515-8

40 Allen MR and Burr DB: Human femoral neck has less cellular periosteum, and more mineralized periosteum, than femoral diaphyseal bone. Bone 36(2): 311-316, 2005. PMID: 15780957. DOI: $10.1016 /$ j.bone.2004.10.013

41 McGrath BE, Bush CH, Nelson TE and Scarborough MT: Evaluation of suspected osteoid osteoma. Clin Orthop Relat Res (327): 247-252, 1996. PMID: 8641070. DOI: 10.1097/00003086199606000-00030

42 Gamba JL, Martinez S, Apple J, Harrelson JM and Nunley JA: Computed tomography of axial skeletal osteoid osteomas. AJR Am J Roentgenol 142(4): 769-772, 1984. PMID: 6608238. DOI: 10.2214/ajr.142.4.769

43 Assoun J, Richardi G, Railhac JJ, Baunin C, Fajadet P, Giron J, Maquin P, Haddad $\mathrm{J}$ and Bonnevialle P: Osteoid osteoma: MR imaging versus CT. Radiology 191(1): 217-223, 1994. PMID: 8134575. DOI: 10.1148/radiology.191.1.8134575

44 de Chadarévian JP, Katsetos CD, Pascasio JM, Geller E and Herman MJ: Histological study of osteoid osteoma's blood supply. Pediatr Dev Pathol 10(5): 358-368, 2007. PMID: 17929985. DOI: $10.2350 / 06-07-0133.1$

45 Yaniv G, Shabshin N, Sharon M, Liberman B, Garniack A, Rimon U and Eshed I: Osteoid osteoma - the CT vessel sign. Skeletal Radiol 40(10): 1311-1314, 2011. PMID: 21484325. DOI: $10.1007 / \mathrm{s} 00256-011-1150-2$

46 Pottecher P, Sibileau E, Aho S, Hamze B, Parlier C, Laredo JD and Bousson V: Dynamic contrast-enhanced MR imaging in osteoid osteoma: relationships with clinical and CT characteristics. Skeletal Radiol 46(7): 935-948, 2017. PMID: 28401265. DOI: $10.1007 / \mathrm{s} 00256-017-2645-2$

47 Liu PT, Kujak JL, Roberts CC and de Chadarevian JP: The vascular groove sign: a new CT finding associated with osteoid osteomas. AJR Am J Roentgenol 196(1): 168-173, 2011. PMID: 21178063. DOI: $10.2214 /$ AJR.10.4534

48 Davies M, Cassar-Pullicino VN, Davies AM, McCall IW and Tyrrell PN: The diagnostic accuracy of MR imaging in osteoid osteoma. Skeletal Radiol 31(10): 559-569, 2002. PMID: 12324824. DOI: $10.1007 / \mathrm{s} 00256-002-0546-4$

49 Liu PT, Chivers FS, Roberts CC, Schultz CJ and Beauchamp $\mathrm{CP}$ : Imaging of osteoid osteoma with dynamic gadoliniumenhanced MR imaging. Radiology 227(3): 691-700, 2003. PMID: 12773675. DOI: 10.1148/radiol.2273020111

50 Teixeira PA, Chanson A, Beaumont M, Lecocq S, Louis M, Marie B, Sirveaux F and Blum A: Dynamic MR imaging of osteoid osteomas: correlation of semiquantitative and quantitative perfusion parameters with patient symptoms and treatment outcome. Eur Radiol 23(9): 2602-2611, 2013. PMID: 23695220. DOI: 10.1007/s00330-013-2867-1

51 Woods ER, Martel W, Mandell SH and Crabbe JP: Reactive softtissue mass associated with osteoid osteoma: correlation of MR imaging features with pathologic findings. Radiology 186(1): 221225, 1993. PMID: 8416568. DOI: 10.1148/radiology.186.1.8416568 
52 Spouge AR and Thain LM: Osteoid osteoma: MR imaging revisited. Clin Imaging 24(1): 19-27, 2000. PMID: 11120413. DOI: $10.1016 / \mathrm{s} 0899-7071(00) 00157-1$

53 Tepelenis K, Papathanakos G, Kitsouli A, Troupis T, Barbouti A, Vlachos K, Kanavaros P and Kitsoulis P: Osteochondromas: An updated review of epidemiology, pathogenesis, clinical presentation, radiological features and treatment options. In Vivo 35(2): 681-691, 2021. PMID: 33622860. DOI: 10.21873/ invivo. 12308

54 Wells RG, Miller JH and Sty JR: Scintigraphic patterns in osteoid osteoma and spondylolysis. Clin Nucl Med 12(1): 39-44, 1987. PMID: 3815995. DOI: 10.1097/00003072-19870100000010

55 Park JH, Pahk K, Kim S, Lee SH, Song SH and Choe JG: Radionuclide imaging in the diagnosis of osteoid osteoma. Oncol Lett 10(2): 1131-1134, 2015. PMID: 26622638. DOI: $10.3892 / \mathrm{ol} .2015 .3258$

56 Helms CA: Osteoid osteoma. The double density sign. Clin Orthop Relat Res (222): 167-173, 1987. PMID: 3621716.

57 Roach PJ, Connolly LP, Zurakowski D and Treves ST: Osteoid osteoma: comparative utility of high-resolution planar and pinhole magnification scintigraphy. Pediatr Radiol 26(3): 222225, 1996. PMID: 8599015. DOI: 10.1007/BF01405305

58 Mariani G, Bruselli L, Kuwert T, Kim EE, Flotats A, Israel O, Dondi $\mathrm{M}$ and Watanabe $\mathrm{N}$ : A review on the clinical uses of SPECT/CT. Eur J Nucl Med Mol Imaging 37(10): 1959-1985, 2010. PMID: 20182712. DOI: 10.1007/s00259-010-1390-8

59 Farid K, El-Deeb G and Caillat Vigneron N: SPECT-CT improves scintigraphic accuracy of osteoid osteoma diagnosis. Clin Nucl Med 35(3): 170-171, 2010. PMID: 20173448. DOI: 10.1097/RLU.0b013e3181cc648f

60 Squier SB, Lewis JI, Accurso JM and Jain MK: 99mTc-methylene diphosphonate single-photon emission computed tomography/computed tomography improves the diagnostic accuracy of osteoid osteoma. Indian J Nucl Med 31(4): 298-300, 2016. PMID: 27833319. DOI: 10.4103/0972-3919.187459

61 Sharma P, Mukherjee A, Karunanithi S, Nadarajah J, Gamanagatti S, Khan SA, Bal C and Kumar R: 99mTcMethylene diphosphonate SPECT/CT as the one-stop imaging modality for the diagnosis of osteoid osteoma. Nucl Med Commun 35(8): 876-883, 2014. PMID: 24751704. DOI: 10.1097/MNM.0000000000000134

62 Lim CH, Park YH, Lee SY and Chung SK: F-18 FDG uptake in the nidus of an osteoid osteoma. Clin Nucl Med 32(8): 628-630, 2007. PMID: 17667437. DOI: 10.1097/RLU.0b013e3180a1 acf3

63 Imperiale A, Moser T, Ben-Sellem D, Mertz L, Gangi A and Constantinesco A: Osteoblastoma and osteoid osteoma: morphofunctional characterization by MRI and dynamic F-18 FDG PET/CT before and after radiofrequency ablation. Clin Nucl Med 34(3): 184-188, 2009. PMID: 19352289. DOI: 10.1097/RLU.0b013e3181966de6

64 De Filippo M, Russo U, Papapietro VR, Ceccarelli F, Pogliacomi F, Vaienti E, Piccolo C, Capasso R, Sica A, Cioce F, Carbone M, Bruno F, Masciocchi C and Miele V: Radiofrequency ablation of osteoid osteoma. Acta Biomed 89(1-S): 175-185, 2018. PMID: 29350646. DOI: 10.23750/abm.v89i1-S.7021

65 Pettine KA and Klassen RA: Osteoid-osteoma and osteoblastoma of the spine. J Bone Joint Surg Am 68(3): 354-361, 1986. PMID: 3949831.
66 Kirchner B, Hillmann A, Lottes G, Sciuk J, Bartenstein P, Winkelmann $\mathrm{W}$ and Schober O: Intraoperative, probe-guided curettage of osteoid osteoma. Eur J Nucl Med 20(7): 609-613, 1993. PMID: 8370382. DOI: 10.1007/BF00176556

67 Carpintero-Benitez P, Aguirre MA, Serrano JA and Lluch M: Effect of rofecoxib on pain caused by osteoid osteoma. Orthopedics 27(11): 1188-1191, 2004. PMID: 15566132.

68 Bottner F, Roedl R, Wortler K, Grethen C, Winkelmann W and Lindner N: Cyclooxygenase-2 inhibitor for pain management in osteoid osteoma. Clin Orthop Relat Res (393): 258-263, 2001. PMID: 11764357. DOI: 10.1097/00003086-20011200000029

69 Bousson V, Leturcq T, Ea HK, Hauger O, Mehsen-Cetre N, Hamzé B, Parlier-Cuau C, Laredo JD, Schaeverbeke T and Orcel P: An open-label, prospective, observational study of the efficacy of bisphosphonate therapy for painful osteoid osteoma. Eur Radiol 28(2): 478-486, 2018. PMID: 28884296. DOI: 10.1007/s00330-017-5019-1

70 Marwan YA, Abatzoglou S, Esmaeel AA, Alqahtani SM, Alsulaimani SA, Tanzer M and Turcotte RE: Hip arthroscopy for the management of osteoid osteoma of the acetabulum: a systematic review of the literature and case report. BMC Musculoskelet Disord 16: 318, 2015. PMID: 26497395. DOI: 10.1186/s12891-015-0779-8

71 Kadhim M, Binitie O, O’Toole P, Grigoriou E, De Mattos CB and Dormans JP: Surgical resection of osteoid osteoma and osteoblastoma of the spine. J Pediatr Orthop B 26(4): 362-369, 2017. PMID: 27832013. DOI: 10.1097/BPB .0000000000000406

72 Fujiwara T, Kunisada T, Takeda K, Hasei J, Nakata E, Mochizuki Y, Kiyono M, Yoshida A and Ozaki T: Mini-open excision of osteoid osteoma using intraoperative O-arm/Stealth navigation. J Orthop Sci 24(2): 337-341, 2019. PMID: 30857616. DOI: 10.1016/j.jos.2018.09.017

73 Towbin R, Kaye R, Meza MP, Pollock AN, Yaw K and Moreland M: Osteoid osteoma: percutaneous excision using a CT-guided coaxial technique. AJR Am J Roentgenol 164(4): 945-949, 1995. PMID: 7726054. DOI: 10.2214/ajr.164.4.7726054

74 Roger B, Bellin MF, Wioland M and Grenier P: Osteoid osteoma: CT-guided percutaneous excision confirmed with immediate follow-up scintigraphy in 16 outpatients. Radiology 201(1): 239-242, 1996. PMID: 8816550. DOI: 10.1148/radiology.201.1.8816550

75 Campanacci M, Ruggieri P, Gasbarrini A, Ferraro A and Campanacci L: Osteoid osteoma. Direct visual identification and intralesional excision of the nidus with minimal removal of bone. J Bone Joint Surg Br 81(5): 814-820, 1999. PMID: 10530842. DOI: $10.1302 / 0301-620 x .81 b 5.9313$

76 Donahue F, Ahmad A, Mnaymneh W and Pevsner NH: Osteoid osteoma. Computed tomography guided percutaneous excision. Clin Orthop Relat Res (366): 191-196, 1999. PMID: 10627735.

77 Sans N, Galy-Fourcade D, Assoun J, Jarlaud T, Chiavassa H, Bonnevialle P, Railhac N, Giron J, Morera-Maupomé H and Railhac JJ: Osteoid osteoma: CT-guided percutaneous resection and follow-up in 38 patients. Radiology 212(3): 687-692, 1999. PMID: 10478233. DOI: 10.1148/radiology.212.3.r99se06687

78 Raux S, Abelin-Genevois K, Canterino I, Chotel F and Kohler $\mathrm{R}$ : Osteoid osteoma of the proximal femur: treatment by percutaneous bone resection and drilling (PBRD). A report of 44 cases. Orthop Traumatol Surg Res 100(6): 641-645, 2014. PMID: 25217029. DOI: 10.1016/j.otsr.2014.05.017 
79 Lindner NJ, Ozaki T, Roedl R, Gosheger G, Winkelmann W and Wörtler K: Percutaneous radiofrequency ablation in osteoid osteoma. J Bone Joint Surg Br 83(3): 391-396, 2001. PMID: 11341426. DOI: $10.1302 / 0301-620 x .83 b 3.11679$

80 Woertler K, Vestring T, Boettner F, Winkelmann W, Heindel W and Lindner N: Osteoid osteoma: CT-guided percutaneous radiofrequency ablation and follow-up in 47 patients. $\mathrm{J}$ Vasc Interv Radiol 12(6): 717-722, 2001. PMID: 11389223. DOI: 10.1016/s1051-0443(07)61443-2

81 Lanza E, Thouvenin Y, Viala P, Sconfienza LM, Poretti D, Cornalba G, Sardanelli F and Cyteval C: Osteoid osteoma treated by percutaneous thermal ablation: when do we fail? A systematic review and guidelines for future reporting. Cardiovasc Intervent Radiol 37(6): 1530-1539, 2014. PMID: 24337349. DOI: 10.1007/s00270-013-0815-8

82 Liu DM, Kee ST, Loh CT, McWilliams J, Ho SG, Brower JS and Munk PL: Cryoablation of osteoid osteoma: two case reports. J Vasc Interv Radiol 21(4): 586-589, 2010. PMID: 20138545. DOI: 10.1016/j.jvir.2009.12.389

83 Santiago E, Pauly V, Brun G, Guenoun D, Champsaur P and Le Corroller T: Percutaneous cryoablation for the treatment of osteoid osteoma in the adult population. Eur Radiol 28(6): 2336-2344, 2018. PMID: 29294152. DOI: 10.1007/s00330-017-5164-6

84 Whitmore MJ, Hawkins CM, Prologo JD, Marshall KW, Fabregas JA, Yim DB, Monson D, Oskouei SV, Fletcher ND and Williams RS: Cryoablation of osteoid osteoma in the pediatric and adolescent population. J Vasc Interv Radiol 27(2): 232-7; quiz 238, 2016. PMID: 26683456. DOI: 10.1016/j.jvir.2015. 10.005

85 Kostrzewa M, Diezler P, Michaely H, Rathmann N, Attenberger UI, Schoenberg SO and Diehl SJ: Microwave ablation of osteoid osteomas using dynamic MR imaging for early treatment assessment: preliminary experience. J Vasc Interv Radiol 25(1): 106-111, 2014. PMID: 24290095. DOI: 10.1016/j.jvir.2013. 09.009

86 Basile A, Failla G, Reforgiato A, Scavone G, Mundo E, Messina M, Caltabiano G, Arena F, Ricceri V, Scavone A and Masala S: The use of microwaves ablation in the treatment of epiphyseal osteoid osteomas. Cardiovasc Intervent Radiol 37(3): 737-742, 2014. PMID: 23989501. DOI: 10.1007/s00270-013-0722-z
87 Hinshaw JL, Lubner MG, Ziemlewicz TJ, Lee FT Jr and Brace CL: Percutaneous tumor ablation tools: microwave, radiofrequency, or cryoablation - what should you use and why? Radiographics 34(5): 1344-1362, 2014. PMID: 25208284. DOI: $10.1148 / \mathrm{rg} .345140054$

88 Geiger D, Napoli A, Conchiglia A, Gregori LM, Arrigoni F, Bazzocchi A, Busacca M, Moreschini O, Mastantuono M, Albisinni U, Masciocchi C and Catalano C: MR-guided focused ultrasound (MRgFUS) ablation for the treatment of nonspinal osteoid osteoma: a prospective multicenter evaluation. J Bone Joint Surg Am 96(9): 743-751, 2014. PMID: 24806011. DOI: 10.2106/JBJS.M.00903

89 Yarmolenko PS, Eranki A, Partanen A, Celik H, Kim A, Oetgen M, Beskin V, Santos D, Patel J, Kim PCW and Sharma K: Technical aspects of osteoid osteoma ablation in children using MR-guided high intensity focussed ultrasound. Int J Hyperthermia 34(1): 49-58, 2018. PMID: 28540807. DOI: 10.1080/02656736.2017.1315458

90 Sluga M, Windhager R, Pfeiffer M, Dominkus M and Kotz R: Peripheral osteoid osteoma. Is there still a place for traditional surgery? J Bone Joint Surg Br 84(2): 249-251, 2002. PMID: 11922367. DOI: 10.1302/0301-620x.84b2.12347

91 Tordjman M, Perronne L, Madelin G, Mali RD and Burke C: CT-guided radiofrequency ablation for osteoid osteomas: a systematic review. Eur Radiol 30(11): 5952-5963, 2020. PMID: 32518986. DOI: 10.1007/s00330-020-06970-y

Received March 23, 2021

Revised April 19, 2021

Accepted April 20, 2021 